\title{
Prevalence of adherence to cardiovascular drugs in outpatients with coronary artery disease
}

\author{
Maria Martins CRUZEIRO' ${ }^{1}$ (D) , Ronara de Souza GROIA-VELOSO² (D), Bianca Menezes DIAS ${ }^{2}$ (D) , Adriano Max REIS ${ }^{1}$ (D) \\ ${ }^{1}$ Faculdade de Farmácia da Universidade Federal de Minas Gerais, Belo Horizonte, MG - Brasil; ${ }^{2}$ Hospital das Clínicas da Universidade Federal \\ de Minas Gerais, Belo Horizonte, MG - Brasil
}

Corresponding author: Groia-Veloso RS, rgroia@yahoo.com.br

Submitted: 05-02-2020 Resubmitted: 09-05-2020 Accepted: 04-06-2020

Peer review: blind reviewer and Thiago Botelho Azeredo

\begin{abstract}
Objectives: To describe the prevalence of adherence to drug treatment and the association with sociodemographic, clinical and pharmacotherapeutic factors, in patients diagnosed with coronary artery disease, seen at a multiprofessional cardiology clinic in a public hospital in Belo Horizonte, Minas Gerais. Methods: This is a cross-sectional study conducted between April 2018 and February 2019 in a multiprofessional outpatient cardiology clinic at a teaching hospital. The dependent variable is adherence to treatment with cardiovascular drugs measured by self-report using the 7-day recall and the independent variables evaluated were the sociodemographic, clinical and pharmacotherapeutic variables. Descriptive analysis was performed using frequency distributions for categorical variables and measures of central tendency and dispersion for continuous variables. The association between treatment adherence and independent variables was performed using bivariate analysis using Pearson's chi-square test and the magnitude of the association was expressed by the odds ratio with a 95\% confidence interval. Results: 148 patients with a median age of 62 years (IQR $=17.0)$, mostly male $(104 ; 70.3 \%)$ and a median of four years of education (IQR $=4.0)$. The most prevalent cardiovascular diagnosis was ST-segment elevation acute myocardial infarction $(58.8 \%)$, followed by non-ST-segment elevation acute myocardial infarction (26.4\%) and arrhythmia (23.7\%). The most frequent comorbidities were hypertension $(72.3 \%)$ and diabetes $(33.1 \%)$. Beta-blockers $98.1 \%(n=130)$ and renin-angiotensin system agents $68.3 \%(n=101)$ were the most commonly used cardiovascular drug classes. No statistically significant association was identified between adherence and sociodemographic, clinical and pharmacotherapeutic factors. Conclusion: The frequency of adherence to treatment measured by 7-days recall was high.
\end{abstract}

Keywords: medication adherence, cardiovascular diseases, coronary artery disease, drug utilization.

\section{Prevalência de adesão aos medicamentos cardiovasculares em pacientes ambulatoriais com doença arterial coronariana}

\begin{abstract}
Resumo
Objetivos: Descrever a prevalência da adesão ao tratamento medicamentoso e a associação com fatores sociodemográficos, clínicos e farmacoterapêuticos, em pacientes com diagnóstico de doença arterial coronariana, atendidos em um ambulatório multiprofissional de cardiologia de um hospital público de Belo Horizonte, Minas Gerais. Métodos: Trata-se de um estudo transversal realizado entre abril de 2018 a fevereiro de 2019 em um ambulatório multiprofissional de cardiologia de um hospital de ensino. A variável dependente é a adesão ao tratamento com medicamentos cardiovasculares mensurada por meio do autorrelato utilizando o 7- days recall e as variáveis independentes avaliadas foram as variáveis sociodemográficas, clínicas e farmacoterapêuticas. A análise descritiva foi realizada por meio de distribuições de frequência para as variáveis categóricas e medidas de tendência central e de dispersão para as variáveis contínuas. A associação entre adesão ao tratamento e variáveis independentes foi realizada por meio de análise bivariada utilizando-se o teste de qui-quadrado de Pearson e a magnitude da associação foi expressa pelo odds ratio com intervalo de confiança de 95\%. Resultados: Participaram do estudo um total de 148 pacientes com mediana de idade de 62 anos (amplitude interquartil - IQR = 17,0), majoritariamente do gênero masculino (104; 70,3\%) e com mediana de escolaridade de quatro anos (IQR = 4,0). O diagnóstico cardiovascular mais prevalente foi o infarto agudo do miocárdio com elevação do segmento ST (58,8\%), seguido do infarto agudo do miocárdio sem elevação do segmento ST (26,4\%) e arritmia (23,7\%). As comorbidades mais frequentes foram hipertensão $(72,3 \%)$ e diabetes $(33,1 \%)$. Os betabloqueadores $98,1 \%$ ( $n=130)$ e os agentes que atuam no sistema renina angiotensina $68,3 \%$ ( $n=101$ ) foram as classes de medicamentos cardiovasculares mais utilizados Não se identificou associação estatisticamente significativa entre a adesão e os fatores sociodemográficos, clínicos e farmacoterapêuticos. Conclusão: A frequência de adesão aos medicamentos cardiovasculares mensurada pelo 7-days recall foi elevada.
\end{abstract}

Palavras-chave: adesão à medicação, doenças cardiovasculares, doença da artéria coronariana, uso de medicamentos. 


\section{Introduction}

Cardiovascular Diseases (CVDs) have a high prevalence and have been the main cause of death in Brazil since the 1960s. ${ }^{1}$ Ischemic cardiovascular diseases are responsible for approximately $10 \%$ of the expenses with hospital admissions and, in 2017, were responsible for 113,773 deaths. ${ }^{2}$ Among the CVDs, we can highlight coronary artery disease (CAD), which is the result of inadequate oxygen supply and of the reduction or absence of blood flow to the myocardium, and can manifest clinically as acute coronary syndrome (acute myocardial infarction [AMI] and unstable angina) and as stable angina. ${ }^{3}$

The drug treatment for CAD has as main objectives to provide better quality of life, increase survival, and reduce the incidence of $\mathrm{AMI}$ and symptoms of angina. ${ }^{4}$ Cardiovascular drugs such as statins, agents that act on the renin-angiotensin system, beta-blockers, and antiplatelet agents are the basis for the prevention and treatment of CVDs, their use for secondary prophylaxis being described as a contributor to the decline in mortality due to CAD., ${ }^{1,5}$ Adherence to treatment with these drugs reduces the incidence of infarction and increases survival in patients with CAD, the prescription of which is recommended by clinical guidelines. . $^{1,5} 6$

According to the European Society for Patient Adherence, Compliance, and Persistence (ESPACOMP), adherence to drug treatment is the process by which patients use their medications prescribed by a health professional. ${ }^{7-8}$ Non-adherence to drug treatment is an important factor that can negatively impact on the clinical results, in addition to increasing health costs. There are many factors that contribute to non-adherence, such as lack of access to the medication, the cost, the greater number of prescribed medications, the therapeutic regimen, and the disease itself. ${ }^{9}$ Considering that the drugs will not be effective if the patients do not follow the prescribed treatment, adherence becomes relevant to the therapeutic success of drug treatment. ${ }^{10}$

Adherence to cardiovascular drugs is low; international studies have shown that the adherence rate is below $80 \%,{ }^{11,12}$ which leads to an increase in cardiovascular mortality. ${ }^{13}$ There is a scarcity of Brazilian studies on adherence to treatment in patients with $C A D^{14}$, and the knowledge on adherence to treatment in national studies is essential to develop relevant health care strategies in high priority areas, such as CVDs. ${ }^{12}$

This study describes the prevalence of adherence to drug treatment in patients diagnosed with CAD, seen at a multiprofessional cardiology outpatient clinic of a public hospital, as well as the association between adherence to treatment with cardiovascular drugs and sociodemographic, clinical, and pharmacotherapeutic variables.

\section{Methods}

\section{Type and place of study}

A cross-sectional and descriptive study carried out between April 2018 and February 2019 through interviews and consultation of medical records in a multi-professional cardiology outpatient clinic of a public hospital in the city of Belo Horizonte, Minas Gerais.

The hospital is of a university and general nature, and carries out teaching, research, and assistance activities, being a reference in the municipal and state health system in the care of patients with medium and high complexity diseases. Patients with CAD are monitored during hospitalization by the multi-professional cardiology team and, after hospital discharge, are scheduled at the multi-professional cardiology outpatient clinic, and attended by clinical pharmacists, cardiovascular health physiotherapists, and/or cardiologists.

\section{Study population and inclusion and exclusion criteria}

The inclusion criteria were patients aged 18 years old or over, cared for at the multi-professional cardiology outpatient clinic of the studied hospital, diagnosed with CAD, and who used at least one medication. The concept of CAD was defined as the presence of stenosis $\geq 50 \%$ of the diameter of one or more coronary vessels identified by catheterization or diagnosis of $\mathrm{AMI}^{4}$. Patients with difficulty in verbal communication were excluded.

\section{Study population and data collection}

A total of 148 patients participated in the research. Patients were recruited through the list of patients scheduled to be seen at the multi-professional cardiology outpatient clinic. Patients treated at this clinic include new patients admitted (scheduled approximately 30 days after hospital discharge) and those being followed-up. Patients who met the study's inclusion criteria were invited to participate. In case of a positive answer, the patient or caregiver/ family member received and signed the free and informed consent corm. Data collection was carried out through a face-to-face interview, before the pharmaceutical service, in a single meeting conducted by a researcher. When the patient's medications were administered by another person, the interview was conducted with the participation of the patient and the person responsible for administering the medications. Data on the main diagnosis of cardiovascular diseases, cardiovascular risk factors, and other selfreported clinical conditions were supplemented/confirmed in the patient's medical record on the same day of the interview. Data was recorded on a form designed for research purposes.

\section{Study variables}

The dependent variable is adherence to treatment with cardiovascular drugs measured by self-report using 7-days recall. The 7-days recall consists of measuring adherence through the following question: "In the past seven days, how many days did you use the medications?"15

The patients were asked to inform which medications for continuous use they were using. The interviewer selected the cardiovascular drugs and, for each of the cardiovascular medications, the question was asked to measure adherence. The patients who used all the cardiovascular drugs for six or seven days were considered adherent, since in this study the cutoff point adopted was $80 \%$ adherence. The patients who used at least one cardiovascular medication for five days or less were classified as non-adherent. ${ }^{13}$ The component of adherence assessed was implementation, and the period of adherence assessed were the last seven days preceding the interview. ${ }^{8,16}$

The independent variables evaluated were the sociodemographic, clinical, and pharmacotherapeutic variables. The sociodemographic variables included in the study were gender, 
age, marital status, and schooling. The clinical variables of the study were main cardiovascular diagnosis and cardiovascular risk factors (hypertension, diabetes, obesity [Body Mass Index equal to or greater than $30 \mathrm{~kg} / \mathrm{m} 2]$ ), and family history of CAD. ${ }^{4}$ The number of diseases was also determined. The perception of the self-reported health condition was determined using a Likert-type scale with the following options: very good, good, regular, bad, or very bad. ${ }^{17}$ The "very good" and "good" options were considered as positive responses. The pharmacotherapeutic variables related to the study were the classification of cardiovascular drugs performed according to the second ${ }^{19}$ level (therapeutic) and to the fourth level (chemical) of the Anatomical Therapeutic Chemical (ATC) classification of the World Health Organization, as well as according to the number of drugs used by patients. ${ }^{18}$ The number of medications used by the patients was reclassified into polypharmacy (use of five or more medications), and the number of cardiovascular drugs into cardiovascular polypharmacy (use of five or more cardiovascular drugs). ${ }^{19}$ The complexity of the pharmacotherapy was measured using the Medication Regimen Complexity Index (MRCI), validated in Brazil. ${ }^{20}$

\section{Database and statistical analysis}

The database was developed using the Epidata 3.1 software. Data insertion was performed using double typing by different researchers. Descriptive analysis was performed using frequency distributions for categorical variables and measures of central tendency and dispersion for continuous variables.

The variables were evaluated in relation to normal distribution using the Kolmogorov-Smirnov test. The continuous variables were dichotomized by their median. The association between treatment adherence and independent variables was performed using bivariate analysis by means of Pearson's chi-square test. In the presence of at least one expected frequency below 5 (five), Fisher's exact test was used. The magnitude of the association was expressed by the Odds Ratio (OR) with a 95\% Confidence Interval (Cl). The statistical analysis was performed using the Statistical Package for Social Sciences ${ }^{\circledR}\left(\right.$ SPSS $\left.^{\circledR}\right)$ software, version 25.0.

\section{Ethical considerations}

The research was conducted according to Resolution 466/12 of the National Health Council - Ministry of Health. ${ }^{21}$ The research was approved by the Research Ethics Committee of the Federal University of Minas Gerais, under number 2.576.504-18.

\section{Results}

The study included 148 patients diagnosed with CAD seen in the outpatient clinic under study. The median age of the patients was 62 years old, with an interquartile range (IQR) of 17.0 years old, and approximately $90 \%$ of the patients were aged 75 years old or less. The study patients were mostly male $(104 ; 70.3 \%)$ and had a median schooling level of four years (IQR =4.0).

As for the clinical characteristics, $75.7 \%(n=112)$ of the research participants had a positive family history for CAD, and $92.6 \%$ ( $n=137)$ assessed their health positively. The most prevalent cardiovascular diagnosis was ST-segment Elevation Acute Myocardial Infarction (STEMI) (58.8\%), followed by Non-ST- segment Elevation Acute Myocardial Infarction (NSTEMI) (26.4\%) and by arrhythmia (23.7\%). The most frequent comorbidities were hypertension (72.3\%), dyslipidemia (44.6\%), and diabetes (33.1\%). The other sociodemographic, lifestyle, and clinical characteristics are shown in Table 1.

Table 1. Lifestyle, sociodemographic, clinical, and pharmacotherapeutic characteristics of the 148 patients with coronary artery disease treated in a cardiology outpatient clinic of a teaching hospital.

\begin{tabular}{lc}
\hline Characteristics & Value \\
\hline Sociodemographic Characteristics & \\
Age in years old [median (interquartile range - IQR)] & $62(17.0)$ \\
Age $\leq 75$ years old [n, (\%)] & $129(87.2)$ \\
Male gender [n, (\%)] & $104(70.3)$ \\
With a partner [n, (\%)] & $93(62.8)$ \\
Schooling in years [median (interquartile range - IQR)] & $4(4.0)$ \\
Clinical Characteristics & \\
Number of health problems [median (interquartile range & \\
- IQR)] & $5(3.0)$ \\
Positive health self-perception [n, (\%)] & $137(92.6)$ \\
Family history of CAD ${ }^{4}$ [n, (\%)] & $112(75.7)$ \\
Cardiovascular Diagnoses & \\
STEMI ${ }^{1}$ [n, (\%)] & $87(58.8)$ \\
NSTEMI ${ }^{2}$ [n, (\%)] & $39(26.4)$ \\
Arrhythmia [n, (\%)] & $35(23.7)$ \\
Heart Failure [n, (\%)] & $29(19.6)$ \\
Unstable angina [n, (\%)] & $16(10.8)$ \\
CVA ${ }^{3}$ [n, (\%)] & $14(9.5)$ \\
Stable angina [n, (\%)] & $11(7.4)$ \\
Health Problems & \\
Systemic Arterial Hypertension [n, (\%)] & $107(72.3)$ \\
Dyslipidemia [n, (\%)] & $66(44.6)$ \\
Diabetes Mellitus [n, (\%)] & $49(33.1)$ \\
\hline
\end{tabular}

${ }^{1}$ STEMI: ST-segment Elevation Acute Myocardial Infarction; ${ }^{2}$ NSTEMI: Non-ST-segment Elevation Acute Myocardial Infarction; ${ }^{3}$ CVA: Stroke; ${ }^{4}$ CAD: Coronary Artery Disease; ${ }^{5}$ BMI: Body Mass Index.

Beta blockers (98.1\%; $n=130)$ and the agents that act on the renin angiotensin system $(68.3 \% ; n=101)$ were the classes of cardiovascular drugs most used by the patients treated in the outpatient clinic. Table 2 shows the anatomical therapeutic chemical classification of the cardiovascular drugs used by the 148 patients.

The frequencies of polypharmacy (use of $\geq 5$ drugs) and cardiovascular polypharmacy (use of $\geq 5$ cardiovascular drugs) were $91.2 \%(n=135)$ and $74.3 \%(n=110)$, respectively. Although the result obtained for polypharmacy is not statistically significant ( $p=0.694 ;$ OR: $0.48 ; 95 \% \mathrm{Cl}: 0.06-3.89$ ), there was a higher frequency of adherence in the patients without polypharmacy, 92.3\% $(n=12)$, than in those with polypharmacy, $85.2 \%(n=115)$.

The patients classified as having high complexity of pharmacotherapy had a lower frequency of adherence, $83.0 \%$ (n =93), than those identified with low or intermediate complexity of pharmacotherapy, 92.0\% $(n=46)$, although these values are not statistically significant ( $p=0.131 ;$ OR: $0.43 ; 95 \% \mathrm{Cl}: 0.14-1.32$ ). 
Table 2. Anatomical Therapeutic Chemical Classification of the Cardiovascular System medications used by the 148 patients with coronary artery disease treated in a cardiology outpatient clinic of a teaching hospital

\begin{tabular}{|c|c|c|c|}
\hline \multicolumn{2}{|c|}{ ATC classification } & $\mathbf{n}$ & $\%$ \\
\hline \multicolumn{4}{|c|}{ Cardiovascular System } \\
\hline $\mathrm{CO1}$ & Cardiac Therapy & 13 & 8.8 \\
\hline C01AA & Digitalis glycosides: digoxin & 4 & 2.7 \\
\hline C01DA & Organic nitrates & 9 & 6.1 \\
\hline $\mathrm{CO3}$ & Diuretics & 53 & 35.8 \\
\hline C03CA & Simple sulfonamides: furosemide & 37 & 25.0 \\
\hline C03AA & Simple thiazides: hydrochlorothiazide & 16 & 10.8 \\
\hline $\mathrm{CO7}$ & Beta-blocking agents & 130 & 98.1 \\
\hline C07AA & Non-selective beta-blocking agents: propranolol & 5 & 3.8 \\
\hline C07AB & $\begin{array}{l}\text { Selective beta-blocking agents: atenolol, } \\
\text { metprolol and nebivolol }\end{array}$ & 67 & 50.0 \\
\hline C07AG & Alpha and beta-blocking agents: carvedilol & 58 & 44.3 \\
\hline $\mathrm{C08}$ & Calcium channel blockers & 40 & 27.0 \\
\hline C08CA & Dihydropyridines: amlodipine & 34 & 22.9 \\
\hline C08DA & Phenylalkylamine derivatives: verapamil & 1 & 0.7 \\
\hline C08DB & Benzathiazepine derivatives: diltiazem & 5 & 3.4 \\
\hline C09CA & $\begin{array}{l}\text { Blockers of the renin-angiotensin system: } \\
\text { losartan }\end{array}$ & 47 & 31.8 \\
\hline
\end{tabular}

It was identified that $85.8 \%(n=127)$ of the participants were classified as adhering to the cardiovascular treatment as measured using the 7-days recall.

With regard to the bivariate analysis, shown in Table 3, no statistically significant association was identified between adherence and the variables studied.

\section{Discussion}

The frequency of adherence to the treatment with cardiovascular drugs measured by self-report through the 7-days recall was high among the patients diagnosed with CAD treated in the studied cardiology outpatient clinic. A study conducted with 92 patients in a secondary prevention clinic for CAD in Rio Grande do Sul, in which adherence to therapy was measured by the Morisky test, identified $56.5 \%$ adherence to the pharmacological therapy, showing low adherence to the treatment of secondary prevention of coronary artery disease. ${ }^{14}$ The absence of national and international studies on adherence with a record period of seven days makes it difficult to compare the results.

Table 3. Bivariate analysis of the factors associated with adherence to cardiovascular drugs through the 7-days recall of the 148 patients with coronary artery disease treated in a teaching hospital (Continued)

\begin{tabular}{|c|c|c|c|c|}
\hline \multirow{3}{*}{$\begin{array}{l}\text { Description } \\
\text { Variable }\end{array}$} & \multirow{2}{*}{\multicolumn{2}{|c|}{$\begin{array}{l}\text { Adherence to treatment } \\
\qquad \text { Frequency }^{1}\end{array}$}} & \multirow{3}{*}{$\begin{array}{l}\text { Bivariate analysis } \\
\text { Odds Ratio (95\% Cl) }\end{array}$} & \multirow[b]{3}{*}{ p-value } \\
\hline & & & & \\
\hline & Yes n (\%) & No n (\%) & & \\
\hline \multicolumn{5}{|c|}{ Sociodemographic } \\
\hline \multicolumn{5}{|l|}{ Gender } \\
\hline Male & $91(87.8 \%)$ & $13(12.5 \%)$ & $1.56(0.59-4.07)$ & 0.395 \\
\hline Female & $36(81.8 \%)$ & $8(18.2 \%)$ & 1 & \\
\hline \multicolumn{5}{|l|}{ Age } \\
\hline$\geq 60$ & $74(86.0 \%)$ & $12(14.0 \%)$ & $1.05(0.41-2.66)$ & 0.923 \\
\hline$<60$ & $53(85.5 \%)$ & $9(14.5 \%)$ & 1 & \\
\hline \multicolumn{5}{|l|}{ Partner } \\
\hline Yes & $79(84.9 \%)$ & $14(15.1 \%)$ & $0.82(0.31-2.18)$ & 0.695 \\
\hline No & $48(87.3 \%)$ & $7(12.7 \%)$ & 1 & \\
\hline \multicolumn{5}{|l|}{ Clinical } \\
\hline \multicolumn{5}{|c|}{ Main cardiovascular diagnosis } \\
\hline \multicolumn{5}{|c|}{ Atrial arrhythmia } \\
\hline Yes & $20(95.2 \%)$ & $1(4.8 \%)$ & $3.74(0.47-29.46)$ & $0.310^{*}$ \\
\hline No & $107(84.3 \%)$ & $20(15.7 \%)$ & 1 & \\
\hline \multicolumn{5}{|c|}{ Ventricular arrhythmia } \\
\hline Yes & $11(78.6 \%)$ & $3(21.4 \%)$ & $0.57(0.14-2.24)$ & $0.422 *$ \\
\hline No & $116(86.6 \%)$ & $18(13.4 \%)$ & 1 & \\
\hline \multicolumn{5}{|l|}{$\mathrm{CHF}^{1}$} \\
\hline Yes & $28(96.6 \%)$ & $1(3.4 \%)$ & $5.66(0.73-44.02)$ & $0.077^{*}$ \\
\hline No & $99(83.2 \%)$ & $20(16.8 \%)$ & 1 & \\
\hline \multicolumn{5}{|l|}{ STEMI ${ }^{2}$} \\
\hline Yes & $76(87.4 \%)$ & $11(12.6 \%)$ & $1.36(0.54-3.42)$ & 0.520 \\
\hline No & $51(83.6 \%)$ & $10(16.4 \%)$ & 1 & \\
\hline \multicolumn{5}{|l|}{ NSTEMI ${ }^{3}$} \\
\hline Yes & $35(89.7 \%)$ & 4 (10.3\%) & $1.62(0.51-5.14)$ & 0.412 \\
\hline No & $92(84.4 \%)$ & $17(15.6 \%)$ & 1 & \\
\hline \multicolumn{5}{|c|}{ Unstable angina } \\
\hline Yes & $12(75.0 \%)$ & $4(25.0 \%)$ & $0.44(0.13-1.53)$ & $0.247^{*}$ \\
\hline No & $115(87.1 \%)$ & 17 (12.9\%) & 1 & \\
\hline
\end{tabular}


Table 3. Bivariate analysis of the factors associated with adherence to cardiovascular drugs through the 7-days recall of the 148 patients with coronary artery disease treated in a teaching hospital (Concluded)

\begin{tabular}{|c|c|c|c|c|}
\hline \multirow{3}{*}{$\begin{array}{l}\text { Description } \\
\text { Variable }\end{array}$} & \multirow{2}{*}{\multicolumn{2}{|c|}{$\begin{array}{l}\text { Adherence to treatment } \\
\text { Frequency }^{1}\end{array}$}} & \multirow{3}{*}{$\begin{array}{l}\text { Bivariate analysis } \\
\text { Odds Ratio (95\% Cl) }\end{array}$} & \multirow[b]{3}{*}{$p$-value } \\
\hline & & & & \\
\hline & Yes n (\%) & No $n(\%)$ & & \\
\hline \multicolumn{5}{|l|}{ Clinical } \\
\hline \multicolumn{5}{|c|}{ Main cardiovascular diagnosis } \\
\hline \multicolumn{5}{|c|}{ Stable angina } \\
\hline Yes & $9(81.8 \%)$ & $2(18.2 \%)$ & $0.72(0.14-3.61)$ & $0.656^{*}$ \\
\hline No & $118(86.1 \%)$ & $19(13.9 \%)$ & 1 & \\
\hline \multicolumn{5}{|l|}{$\mathrm{CVA}^{4}$} \\
\hline Yes & $13(92.9 \%)$ & $1(7.1 \%)$ & $2.28(0.28-18.42)$ & $0.693^{*}$ \\
\hline No & $114(85.1 \%)$ & $20(14.9 \%)$ & 1 & \\
\hline \multicolumn{5}{|c|}{ Hypertension } \\
\hline Yes & $91(85.0 \%)$ & $16(15.0 \%)$ & $0.79(0.27-2.32)$ & 0.667 \\
\hline No & $36(87.8 \%)$ & $5(12.2 \%)$ & 1 & \\
\hline \multicolumn{5}{|c|}{ Health self-perception } \\
\hline Yes & $117(85.4 \%)$ & $20(14.6 \%)$ & $0.85(0.79-0.92)$ & $0.593^{*}$ \\
\hline No & $7(100 \%)$ & $0(0 \%)$ & 1 & \\
\hline \multicolumn{5}{|l|}{ Diabetes } \\
\hline Yes & $42(85.7 \%)$ & $7(14.3 \%)$ & $0.99(0.37-2.63)$ & 0.981 \\
\hline No & 85 (85.9\%) & $14.1(21 \%)$ & 1 & \\
\hline \multicolumn{5}{|l|}{ Obesity } \\
\hline Yes & $19(95.0 \%)$ & $1(5.0 \%)$ & $3.52(0.44-27.79)$ & $0.309 *$ \\
\hline No & $108(84.4 \%)$ & $20(15.6 \%)$ & 1 & \\
\hline \multicolumn{5}{|c|}{ Family history of $C A D^{5}$} \\
\hline Yes & $95(84.8 \%)$ & $17(15.2 \%)$ & $0.69(0.22-2.23)$ & 0.543 \\
\hline No & $32(88.9 \%)$ & $4(11.1 \%)$ & 1 & \\
\hline \multicolumn{5}{|c|}{ Pharmacotherapeutic } \\
\hline \multicolumn{5}{|c|}{ Polypharmacy } \\
\hline Yes & $115(85.2 \%)$ & $20(14.8 \%)$ & $0.48(0.06-3.89)$ & $0.694^{*}$ \\
\hline No & $12(92.3 \%)$ & $1(7.7 \%)$ & 1 & \\
\hline \multicolumn{5}{|c|}{ Cardiovascular polypharmacy } \\
\hline Yes & $92(83.6 \%)$ & $18(16.4 \%)$ & $044(0.12-1.58)$ & 0.197 \\
\hline No & $35(92.1 \%)$ & $3(7.9 \%)$ & 1 & \\
\hline \multicolumn{5}{|c|}{ High complexity } \\
\hline Yes & $93(83.0 \%)$ & 19 (17.0\%) & $0.43(0.14-1.32)$ & 0.131 \\
\hline No & $46(92.0 \%)$ & $4(8.0 \%)$ & 1 & \\
\hline
\end{tabular}

Patients with serious illnesses and polypharmacy, such as those seen in the multi-professional outpatient clinic of the present study, can benefit from educational consultations with a pharmacist. The care provided to the patients by pharmacists can improve the clinical outcomes and the quality of life for those with chronic conditions, as well as reduce the use of health services, such as fewer visits to general practitioners and reduced hospitalization rates. ${ }^{22}$ Interventions by pharmacists, reported in several studies, showed that clinical pharmacy services can contribute to the rationalization of drug therapy and lead to greater safety in the use of the medications. Therefore, in this scenario, the pharmacist can work together with the patient and the multidisciplinary health team, seeking to improve the results of the drug therapy and identifying and solving problems related to the use of medications, such as adherence. ${ }^{23}$

The high adherence rates can also be explained by the fact that the outpatient clinic under study is part of the Program of Best Practice in Cardiology, which advocates the implementation of treatment adherence strategies before hospital discharge. ${ }^{24}$ The high frequency of adherence may also be in consonance with the type of method used to measure adherence. In a study that compared nine studies which evaluated self-report and other measures of adherence, slightly higher estimates of adherence were found in those that used self-report. ${ }^{25}$ However, this result suggests an association with the integrity of the method, which can be considered the patient's tendency to over-report adherence for fear of displeasing the health professionals. ${ }^{25-26}$ This phenomenon of social desirability was minimized in this study with the application of the questionnaire by a professional unrelated to the care provided by the multidisciplinary health team in the studied outpatient clinic.

The self-report of adherence through 7-days recall, an indirect measure, was chosen because it is a simple and low-cost treatment to determine adherence. Self-reporting has been a method used to monitor and acquire information about adherence and, when used in a standardized way, it can produce valuable information about the degree of adherence to treatment. The last seven days as the period for assessing adherence was chosen due to the greater chance that the patient will remember the administration of the drugs in this interval, thus reducing memory bias. However, 
this method is open to criticism, since there are differences in the process for measuring adherence based on self-reports, which makes it difficult to compare studies due to the different methods and approaches used to identify adherence. ${ }^{26-27}$

According to Stirrat et al, 2015, although the seven-day recall is favorable to circumvent memory bias, the 30 -day period has been mentioned as more interesting in methods with criterion validity for clinical outcomes. ${ }^{28}$

It is important to highlight that a meta-analysis published in 2019 with the objective of identifying the predictive performance of the commonly used adherence measures found that self-reporting in the last seven days was a good predictor of non-adherence compared to pill counts. According to the authors, although some studies recommend using a 30-day recall period in self-report surveys, it should also be considered that, as self-report studies are susceptible to memory bias, the shorter the time, the greater the measurement accuracy. ${ }^{16}$

It is also worth mentioning this study considered a cut-off point of $80 \%$ of adherence as appropriate, which may explain the high prevalence of adherence and the absence of associated factors. It is important to consider the possibility of consent bias in the sample. In this sense, the use of a higher adherence cutoff point would result in lower prevalence and, possibly, higher power to distinguish those patients with an optimal medication use profile, from those with less compliance with the recommendations, expanding the capability to identify factors associated with adherence.

Adherence is a dynamic, complex and multidimensional process, which can be measured by different methods. Each method has its own particularities and applicability, making it necessary to assess the reality of the cultural and economic context of the environment in which the study will be carried out. Adherence monitoring can be used as a patient support tool, which allows the health team to identify problems and design interventions according to the needs of each patient. ${ }^{29}$

In a study carried out with the objective of evaluating the beliefs of patients and physicians about medication adherence, it was identified that, although the physicians recognize the importance of discussing adherence with their patients, discussions were uncommon, in addition to detecting a failure by cardiologists to correctly recognize which of their patients were not adherent. ${ }^{9}$ In view of the above, actions that involve inter-professionality are necessary in order to provide comprehensive care to the patient, seeking the creation of strategies to achieve their physical and social well-being.

The frequency of positive self-perceived health was high, but it was not associated with adherence. The National Drug Use Survey analyzed the factors associated with low adherence to the pharmacological treatment of chronic diseases in Brazil and identified that the likelihood of low adherence was about three times higher in those individuals who had poor or very bad selfperceived health. ${ }^{30}$ Thus, self-perceived health can be a factor that influences adherence to drug treatment.

Regarding the sociodemographic factors, the findings of the present study did not show any association between the variables analyzed. However, the literature emphasizes that advanced age, female gender, higher income and schooling show higher adherence to treatment. ${ }^{25}$ Understanding the association between adherence to cardiovascular drugs by patients with CAD and sociodemographic, clinical, and pharmacotherapeutic factors is necessary to guide team actions aiming at the optimization of the therapeutic results and at ensuring adherence to the treatment. In view of this, further studies are needed to better elucidate the variables that interfere with medication adherence among patients with CAD.

The present study has some limitations, such as the sample size and it being conducted in a single outpatient clinic, which may limit the generalization of the results. In this investigation, a bivariate analysis was performed, which, unlike multivariate regression, has the limitation of not providing the identification of multiple variables that operate independently or in conjunction with another to explain the variation in the dependent variable. ${ }^{31}$ Therefore, the identification of factors related to medication adherence in patients with CAD using multivariate regression methods and the inclusion of patients from different outpatient clinics are aspects to be considered in future research studies.

However, it is important to emphasize that this study is innovative since, to the best of our knowledge, it is the first national survey that uses 7-days recall to measure adherence to the treatment with cardiovascular drugs in patients with coronary artery disease using ESACOMP recommendations, such as determining the studied adherence phase, defining the adequate concept of adherence, and using measures to minimize social desirability.

\section{Conclusion}

In the present study, adherence to treatment with cardiovascular drugs measured by self-report over 7 days was recovered, considering the cut-off point of $80 \%$ adherence. No associated factors were observed in the study.

\section{Funding sources}

The research did not receive financing for its realization.

\section{Collaborators}

Groia-Veloso RC and Reis AM participated in the design of the study. Cruzeiro MG, Dias BM and Groia-Veloso RC participated in data collection. Cruzeiro MG and Groia-Veloso RC participated in the writing of the article. Cruzeiro MG, Dias BM, Groia-Veloso RC and Reis AM participated in data analysis and interpretation and carried out a critical review of the article. All the authors approved the version to be published and assumed responsibility for all information included in the paper, ensuring the accuracy and integrity of any its parts.

\section{Acknowledgments}

We thank the entire team in the pharmacy and cardiology sectors of the HC-UFMG for supporting this research, especially Doctor Luiz Guilherme Passaglia and Physiotherapist Patrícia Paulino.

\section{Conflict of interest statement}

The authors declare that there are no conflicts of interest regarding this article. 


\section{References}

1. Ribeiro ALP, Duncan BB, Brant LCC, et al. Cardiovascular Health in Brazil: Trends and Perspectives. Circulation. 2016;133(4):422-33.

2. BRASIL. Ministério da Saúde. Departamento de Informática do SUS- DATASUS. Avaliable in: http://tabnet.datasus.gov.br/ cgi/tabcgi.exe?sih/cnv/ niuf.def. Accessed on: 15 sep. 2019.

3. Wells BG, Dipiro JT, Schwinghammer TL, et al. Manual de farmacoterapia. 9. ed. Porto Alegre: AMGH, 2016.

4. Cesar LA, Ferreira JF, Armaganijan D, et al. Diretriz de Doença Coronária Estável. Arq Bras Cardiol. 2014; 103(2):1-59.

5. Ford ES, Ajani UA, Croft JB, et al. Explaining the decrease in US deaths from coronary disease, 1980-2000. New England Journal of Medicine. 2007; 356(23): 2388-98.

6. Korhonem MJ, Robison JG, Annis IE, et al. Adherence tradeoff to multiple preventive therapies and all-cause mortality after acute myocardial infarction. Journal of the American College of Cardiology. 2017; 70(13): 1543-1554.

7. Vrijens $B$, De Geest $S$, Hugues DA, et al. A new taxonomy for describing and defining adherence to medications. British journal of clinical pharmacology, 2012; 73(5): 691-705.

8. Geest S, Zullig LL, Dunbar-Jacob J, et al. ESPACOMP medication adherence reporting guideline (EMERGE). Ann Intern Med. 2018; 169(1):30 -5.

9. Hines R, Stones NJ. Patients and Physicians Beliefs and Practices Regarding Adherence to Cardiovascular Medication. JAMA Cardiol. 2016; 1(4):470-3.

10. World Health Organization: Adherence to long-term therapies: evidence for action. Geneva: WHO; 2003.

11. Khatib R, Marshall K, Silcock J, et al. Adherence to coronary artery disease secondary prevention medicines: exploring modifiable barriers. Open hear. 2019; 6 (2): 1-10.

12. Kolandaivelu K, Leiden BB, O'Gara PT, et al. Non-adherence to cardiovascular medications. European heart journal. 2014; 35(46): 3267-3276

13. Choudhry NK, Glynn RJ, Avorn J, et al. Untangling the relationship between medication adherence and postmyocardial infarction outcomes: medication adherence and clinical outcomes. American heart journal. 2014; 167(1) 51-58.

14. Lunelli RP, Portal VL, Esmerio VG, et al. Adesão medicamentosa e não medicamentosa de pacientes com doença arterial coronariana. Acta Paul Enferm, 2009; 22(4): 367-73.

15. Sevilla-Cazes J, Finkleman BS, Chen J, et al. Association Between Patient-Reported Medication Adherence and Anticoagulation Control. Am J Med. 2017;130(9): 1092-1098. e2.

16. Almeida-Brasil CC, Moodie EEM, Cardoso TS, et al. Comparison of the predictive performance of adherence measures for virologic failure detection in people living with HIV: a systematic review and pairwise meta-analysis. AIDS care. 2019; 31(6): 647-659.ne Database of Systematic Reviews. 2013; Feb (28): CD010398.
17. Brasil. Ministério da Saúde. Secretaria de Vigilância em Saúde. Departamento de vigilância de doenças e agravos não transmissíveis e promoção da saúdevigilância de fatores de risco e proteção para doenças crônicas por inquérito telefônico - VIGITEL Brasil 2016. Avaliable in: http://bvsms. saude.gov.br/bvs/publicacoes/vigitel_brasil_2016_fatores_ risco.pdf. Accessed in: 23 set. 2019

18. WHO. World Health Organization. Classificação Anatômico Terapêutico Químico. Accessed in: https://www.whocc.no/ atc_ddd_index/. Accessed on: 10 sep. 2019.

19. Feng $X$, Tan X, Riley B, Zheng $T$, et al. Polypharmacy and multimorbidity among medicaid enrollees: A multistate analysis. Population health management. 2018; 21(2): 123-129.

20. Melchior AC, Correr CJ, Fernandes-Llimos, F. Translation and validation into Portuguese language of the medication regimen complexity index. Arquivos brasileiros de cardiologia. 2007; 89(4): 210-218.

21. Brasil. Ministério da Saúde. Resolução 466 № 466, de 12 de dezembro de 2012 do Conselho Nacional de Saúde.

22. Pande $\mathrm{S}$, Hiller JE, Nkansah N, et al. The effect of pharmacist provided non dispensing services on patient outcomes, health service utilisation and costs in low and middle income countries. Cochra

23. Foroughinia F, Tazarehie SR, Petramfar P. Detecting and managing drug-related problems in the neurology ward of a tertiary care teaching hospital in Iran: A clinical pharmacist's intervention. J Res Pharm Pract. 2016;5:285-9.

24. SBC. Sociedade Brasileira de Cardiologia. Boas Práticas Clínicas em Cardiologia. Adesão às Diretrizes Assistenciais de Insuficiência Cardíaca, Fibrilação Atrial e Síndrome Coronariana Aguda : um Programa de Boas Praticas Clínicas em Cardiologia. Avaliable in: <www.cardiol.br/ boaspraticasclinicas>. Accessed on: 09 nov. 2019.

25. Dimatteo MR. Variations in Patients' Adherence to Medical Recommendations A Quantitative Review of 50 Years of Research. Medical care, 2004; 42(3):200-209.

26. Gautério-Abreu DP, Santos SSC, Silva BT, et al. Pessoas idosas em atendimento ambulatorial: motivos que levam a adesão/não adesão aos medicamentos. Texto \& ContextoEnfermagem. 2015; 24(4): 1094-1103.

27. Gabarro Mel. cumplimiento terapêutico. Pharm Care Esp.1999;1:97-106.

28. Stirratt MJ, Dunbar-Jacob J, Crane HM, et al. Selfreport measures of medication adherence behavior: recommendations on optimal use. TBM 2015; 5 (4):470-482.

29. Santa Helena ET, Nemes MIB, Eluf-Neto J. Desenvolvimento e validação de questionário multidimensional para medir nãoadesão ao tratamento com medicamentos. Rev. de Saúde Pública. 2008; 42(4): 764-767.

30. Tavares NUL, Bertoldi AD, Arrais PSD, et al. Fatores associados à baixa adesão ao tratamento farmacológico de doenças crônicas no Brasil. Rev Saude Publica. 2016; 50(2):10s.

31. Lee J, Tan CS, Chia KS. A practical guide for multivariate analysis of dichotomous outcomes. Ann Acad Med Singapore. 2009; 38(8):714-719. 